\title{
Identifikasi Spasial Calon Walikota Manado Tahun 2015 Menggunakan Algoritma Fuzzy C-Means
}

\author{
Winsy Weku ${ }^{1}$, Charitas Fibriani ${ }^{2}$ \\ ${ }^{1}$ Program Studi Matematika, FMIPA, UNSRAT Manado, winsy weku@unsrat.ac.id \\ ${ }^{2}$ Program Studi Ilmu Komputer, Fakultas Teknologi Informasi Universitas Kristen Satya \\ Wacana Salatiga, charitas.fibriani@ staff.uksw.edu
}

\begin{abstract}
Abstrak
Analisis cluster bertujuan untuk mengidentifikasi kelompok-kelompok objek yang sama, dan membantu untuk menemukan distribusi pola dan korelasi menarik dalam set data yang besar. Fuzzy Clustering telah banyak dipelajari dan diterapkan dalam berbagai bidang utama dan validasi fuzzy clustering memainkan peran yang sangat penting dalam fuzzy clustering. Dalam penelitian ini akan dilakukan pengelompokan wilayah kaum pemilih untuk Calon Walikota Manado tahun 2015. Metode yang digunakan adalah algoritma Fuzzy C-Means. Dengan menggunakan 3 cluster dan 2 cluster didapatkan pengelompokkan 28, 18 dan 40 untuk 3 cluster dan pengelompokkan 46 dan 40 untuk 2 cluster. Hasil tersebut dapat dilihat dengan memperhatikan derajat keanggotaan fuzzy-nya.
\end{abstract}

Kata kunci: Calon Walikota, Algoritma Fuzzy C-Means, Geospasial

\section{Spatial Identification of Manado's Candidate Major in 2015 Using Fuzzy C-Means Algorithm}

\begin{abstract}
Cluster analysis aims to identify the groups to the same object, and helping to find distribution patterns and interesting correlation in large data sets. Fuzzy Clustering has been widely studied and applied in many key areas and validation of fuzzy clustering plays a very important role in the fuzzy clustering. In this research will be the regional grouping voters for Mayor Candidate Manado in 2015. The method used is Fuzzy CMeans algorithm. By using 3 clusters and 2 cluster grouping obtained 28, 18 and 40 for the three clusters and the grouping of 46 and 40 for the second cluster. The results can be seen by noting its fuzzy membership degree.
\end{abstract}

Keywords : Major Candidate, Fuzzy C-Means Algorithm, Geospatially

\section{Pendahuluan}

Clustering adalah salah satu pendekatan umum untuk pemodelan deskriptif dari sejumlah besar data, yang memungkinkan analis untuk fokus pada representasi tingkat yang lebih tinggi dari data. metode Clustering menganalisis dan mengeksplorasi dataset untuk mengasosiasikan objek dalam kelompok, sehingga benda-benda di setiap kelompok memiliki karakteristik yang sama. Karakteristik ini dapat dinyatakan dalam berbagai cara: misalnya, satu dapat menggambarkan objek dalam sebuah cluster sebagai penduduk yang dihasilkan oleh distribusi gabungan, atau sebagai sekumpulan objek yang meminimalkan jarak dari pusat massa dari kelompok.

Clustering melibatkan tugas membagi titik data ke dalam kelas homogen atau kelompok sehingga barang-barang di kelas yang sama yang semirip mungkin dan item dalam kelas yang berbeda adalah sebagai berbeda mungkin. Clustering juga dapat dianggap sebagai bentuk kompresi data, di mana sejumlah besar sampel diubah menjadi sejumlah kecil prototipe perwakilan atau cluster. Tergantung pada data dan aplikasi, jenis tindakan kesamaan dapat digunakan untuk mengidentifikasi kelas, di mana ukuran kesamaan mengontrol bagaimana cluster terbentuk. Beberapa contoh nilai-nilai yang dapat digunakan sebagai ukuran kesamaan antara jarak, konektivitas, dan intensitas.

Dalam statistik dan optimasi, masalah biasa untuk memaksimalkan atau meminimalkan fungsi, dan variabel dalam ruang tertentu. Seperti masalah optimasi ini mungkin menganggap 
beberapa jenis, masing-masing dengan karakteristik sendiri, banyak teknik yang telah dikembangkan untuk menyelesaikannya. teknik ini sangat penting dalam Data Mining dan wilayah Knowledge Discovery karena dapat digunakan sebagai dasar untuk sebagian besar metode yang kompleks dan kuat.

\section{Algoritma Fuzzy C-Means}

Fuzzy c-means (FCM) adalah metode clustering yang memungkinkan satu bagian dari data milik dua atau lebih kelompok. Metode ini (yang dikembangkan oleh Dunn pada tahun 1973 dan ditingkatkan oleh Bezdek pada tahun 1981) sering digunakan dalam pengenalan pola. Hal ini didasarkan pada minimalisasi fungsi tujuan berikut [1][2][3][4][5][6]:

$$
J_{m}(\mu, a)=\sum_{j=1}^{n} \sum_{i=1}^{c}\left(\mu_{i j}\right)^{m} d^{2}\left(x_{j}, a_{i}\right)
$$

Dimana bobot eksponen $1<\mathrm{m}<+\infty$ menyajikan tingkat kekaburan dan notasi $d\left(x_{j}, a_{i}\right)$ menunjukkan jarak (perbedaan) ukuran antara $x_{j}$ titik data dan center cluster $a_{i}$. Partisi fuzzy dilakukan melalui optimasi berulang (meminimalkan) dari fungsi tujuan $J_{m}(\mu, a)$, dengan update keanggotaan $\mu_{i j}$ dan pusat cluster $\mathrm{a}_{\mathrm{i}}$ oleh:

$$
\begin{aligned}
a_{i} & =\frac{\sum_{j=1}^{n} \mu_{i j} m_{x_{j}}}{\sum_{j=1}^{n} \mu_{i j}{ }^{m}} \\
\mu_{i j} & =\frac{d\left(x_{j}, a_{i}\right)^{\frac{-2}{m-2}}}{\sum_{k=1}^{c} d\left(x_{j}, a_{k}\right)^{\frac{-2}{m-2}}} \quad \mathrm{i}=1,2, \ldots, \mathrm{c} ; \mathrm{j}=1,2, \ldots, \mathrm{n}
\end{aligned}
$$

Berdasarkan urutan eksekusi untuk tahap s menggunakan stage (s-1) menurut persamaan update (2) dan (3). Prosedur ini konvergen ke minimum lokal atau titik pelana $\mathbf{J}_{\mathrm{m}}$.

Algoritma ini terdiri dari langkah-langkah berikut:

1. Tetapkan $2 \leq c \leq n$ dan tetapkan sembarang $\varepsilon>0$.

Berikan inisialisasi $\mu^{(0)}=\left(\mu_{1}{ }^{(0)}, \ldots, \mu_{c}{ }^{(0)}\right)$ dan misalkan $s=1$.

2. Hitung pusat klaster $a^{(s)}$ dengan $\mu^{(s-1)}$ dimana

$$
a_{i}=\frac{\sum_{j=1}^{n} \mu_{i j}{ }^{m} x_{j}}{\sum_{j=1}^{n} \mu_{i j}{ }^{m}}
$$

3. Update $\mu^{(s)}$ dengan $a^{(s)}$ dimana

$$
\mu_{i j}=\frac{d\left(x_{j}, a_{i}\right)^{\frac{-2}{m-2}}}{\sum_{k=1}^{c} d\left(x_{j}, a_{k}\right)^{\frac{-2}{m-2}}}
$$

4. Bandingkan $\mu^{(s)}$ to $\mu^{(s-1)}$ in a convenient matrix form $\|$. $\|$. IF $\left\|\mu^{(s)}-\mu^{(s-1)}\right\|<\epsilon$, STOP

ELSE $s=s+1$ dan kembali ke langkah 2 .

\section{Pembahasan}

Penelitian ini termasuk contoh analisis geospasial dari dunia nyata: geo-demografis. Ukuran cluster yang dipilih berdasarkan prosedur BIC. Sebagai alat komputasi yang dipilih adalah R, dimana paket $\mathrm{R}$ yang akan digunakan adalah e-1071 dikembangkan oleh David Meyer, tersedia dalam CRAN repositori. Tata Ruang penyajian data dilakukan dengan ArcView.

Contoh analisis data yang akan diamati dalam penelitian ini adalah geodemographic, karena data geodemographic menggunakan beberapa batas administratif dalam kota seperti pada contoh pada Gambar 1.

Peta administrasi kota Manado akan dilakukan analisis cluster untuk melihat mana daerah dikelompokkan secara terpisah dengan mempertimbangkan variabel yang ada, yaitu lokasi, bujur dan lintang, 1 pemilih, 2 pemilih dan 3 pemilih.

Perkiraan untuk mengetahui berapa banyak cluster yang akan digunakan, digunakan Bayesian Information Criteria (BIC). Menurut BIC dalam Gambar 3, perkiraan cluster optimal adalah 3clusters (perhatikan nilai BIC tertinggi dan jumlah entropi plot). 


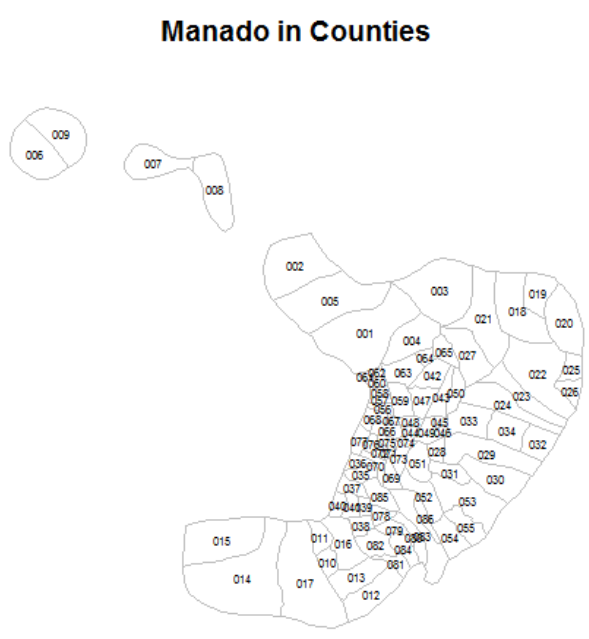

\begin{tabular}{|l|l}
\hline DESA_NO & \multicolumn{1}{|c}{ DESA } \\
\hline 001 & MOLAS \\
\hline 002 & TONGKEINA \\
\hline 003 & PANDU \\
\hline 004 & BAILANG \\
\hline 005 & MERAS \\
\hline 006 & MANADO TUA DUA \\
\hline 007 & ALUNG BANUA \\
\hline 008 & BUNAKEN \\
\hline 009 & MANADO TUA SATU \\
\hline 010 & BATUKOTA \\
\hline 011 & BAHU \\
\hline 012 & WINANGUN1 \\
\hline 013 & WINANGUN2 \\
\hline 014 & MALALAVANG SATU TIMUR \\
\hline 015 & MALALAVANG DUA \\
\hline 016 & KLEAK \\
\hline 017 & MALALAVANG SATU BARAT \\
\hline 018 & KIMAATAS \\
\hline 019 & MAPANGET BARAT \\
\hline 020 & LAPANGAN \\
\hline 021 & BENGKOL \\
\hline 022 & PANIIK BAWAH \\
\hline 023 & KAIRAGI DUA \\
\hline 024 & KAIRAGI SATU \\
\hline 025 & PANIIK1 \\
\hline 026 & PANIII 2 \\
\hline 027 & BUHA \\
\hline 028 & DENDENGAN LUAR \\
\hline & \\
\hline
\end{tabular}

\begin{tabular}{|l|l|}
\hline 029 & PAAL DUA \\
\hline 030 & RANOMUT \\
\hline 031 & DENDENGAN DALAM \\
\hline 032 & MALENDENG \\
\hline 033 & KAIRAGI WERU \\
\hline 034 & PERKAMIL \\
\hline 035 & TITIWUNGEN SELATAN \\
\hline 036 & TITIWUNGEN UTARA \\
\hline 037 & SARIO UTARA \\
\hline 038 & RANOTANA \\
\hline 039 & SARIO KOTA BARU \\
\hline 040 & SARIO TUMPAAN \\
\hline 041 & SARIO \\
\hline 042 & SINGKIL 2 \\
\hline 043 & KOMBOS BARAT \\
\hline 044 & KARAME \\
\hline 045 & TERNATE TANJUNG \\
\hline 046 & TERNATE BARU \\
\hline 047 & SINGKIL 1 \\
\hline 048 & WAWONASA \\
\hline 049 & KETANG BARU \\
\hline 050 & KOMBOS TIMUR \\
\hline 051 & TIKALA ARES \\
\hline 052 & BANJER \\
\hline 053 & TIKALA BARU \\
\hline 054 & TAAS \\
\hline 055 & PAAL 4 \\
\hline 056 & SINDULANG SATU \\
\hline 057 & SINDULANG DUA \\
\hline & \\
\hline
\end{tabular}

\begin{tabular}{|l|l}
\hline 058 & BITUNGKARANGRIA \\
\hline 059 & KAMPUNG ISLAM \\
\hline 060 & MAASING \\
\hline 061 & TUMUMPA2 \\
\hline 062 & TUMUMPA1 \\
\hline 063 & TUMINTING \\
\hline 064 & MAHAWU \\
\hline 065 & SUMOMPO \\
\hline 066 & PINAESAAN \\
\hline 067 & ISTIQLAL \\
\hline 068 & CALACA \\
\hline 069 & TELING BAWAH \\
\hline 070 & BUMI BERINGIN \\
\hline 071 & MAHAKERET BARAT \\
\hline 072 & MAHAKERET TIMUR \\
\hline 073 & TIKALA KUMARAKA \\
\hline 074 & KOMO LUAR \\
\hline 075 & LAWANG IRUNG \\
\hline 076 & WENANG UTARA \\
\hline 077 & WENANG SELATAN \\
\hline 078 & WANEA \\
\hline 079 & BUMI NYIUR \\
\hline 080 & PAKOWA \\
\hline 081 & KAROMBASAN SELATAN \\
\hline 082 & KAROMBASAN UTARA \\
\hline 083 & TELING ATAS \\
\hline 084 & RANOTANA WERU \\
\hline 085 & TANUNG BATU \\
\hline 086 & TINGKULU \\
\hline & \\
\hline
\end{tabular}

Gambar 1. Peta administrasi kotamadya Manado
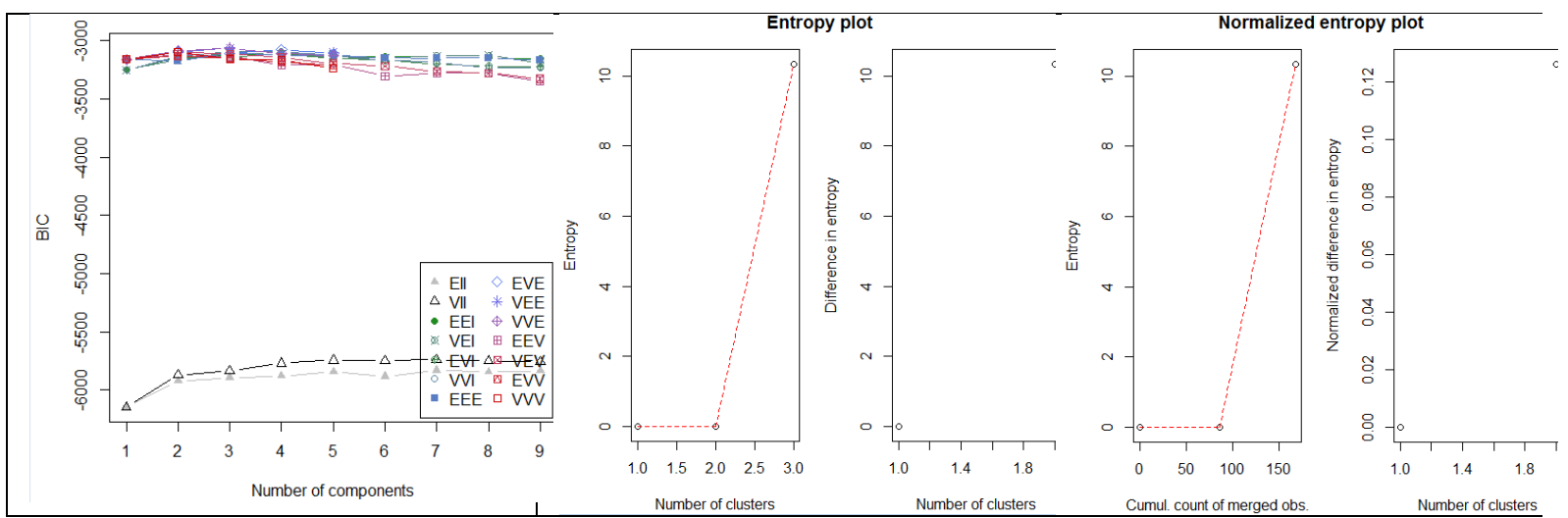

Gambar 2. Ukuran Klaster Optimal dan Entropinya berdasarkan BIC

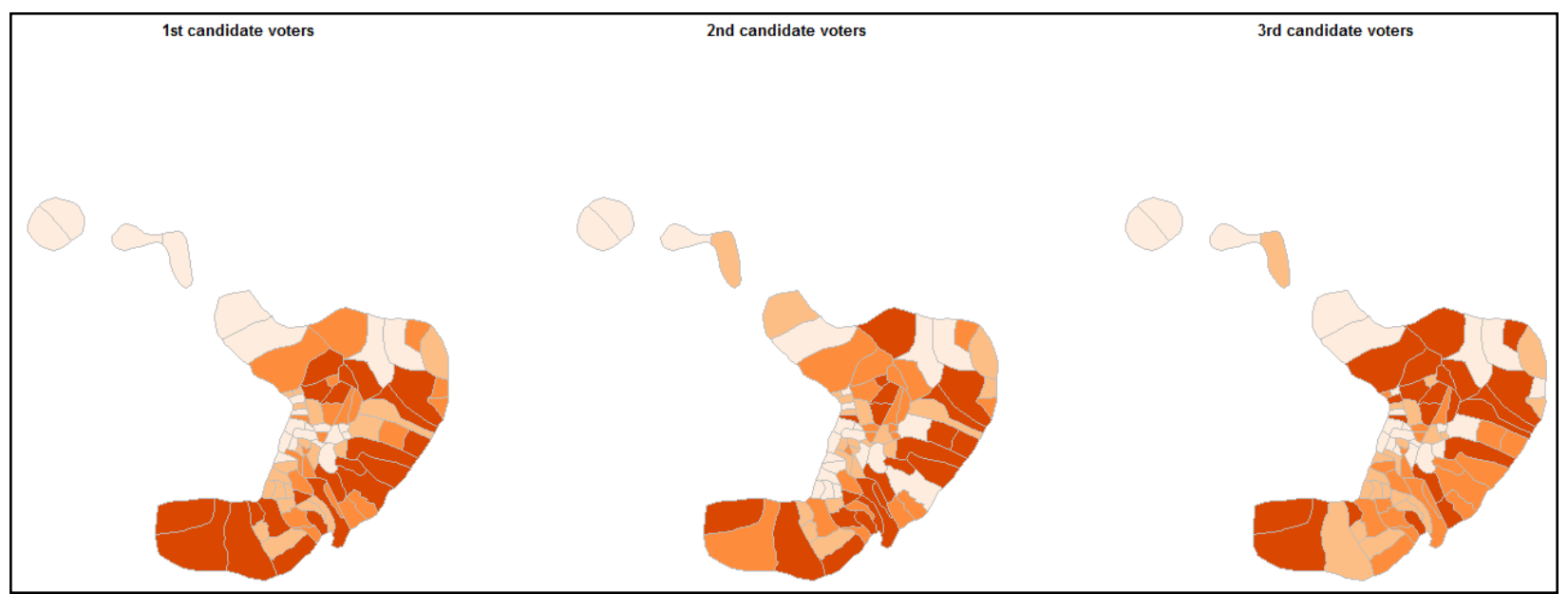

Gambar 3. Keadaan awal para pemilih di Kotamadya Manado berdasarkan wilayah

Berdasarkan keadaan awal dari pemilih, distribusi pemilih didistribusikan baik berarti bahwa semua daerah memiliki pemilih 59anatic. Sementara ada daerah tertentu yang memiliki pemilih umum, misalnya dengan id 015, 022 dan 023 (Malalayang Dua, Paniki Bawah dan Kairagi Dua, masing-masing) berarti bahwa pemilih di tiga wilayah tersebut adalah pemilih tertinggi dan dibagi secara merata kepada semua tiga kandidat . 

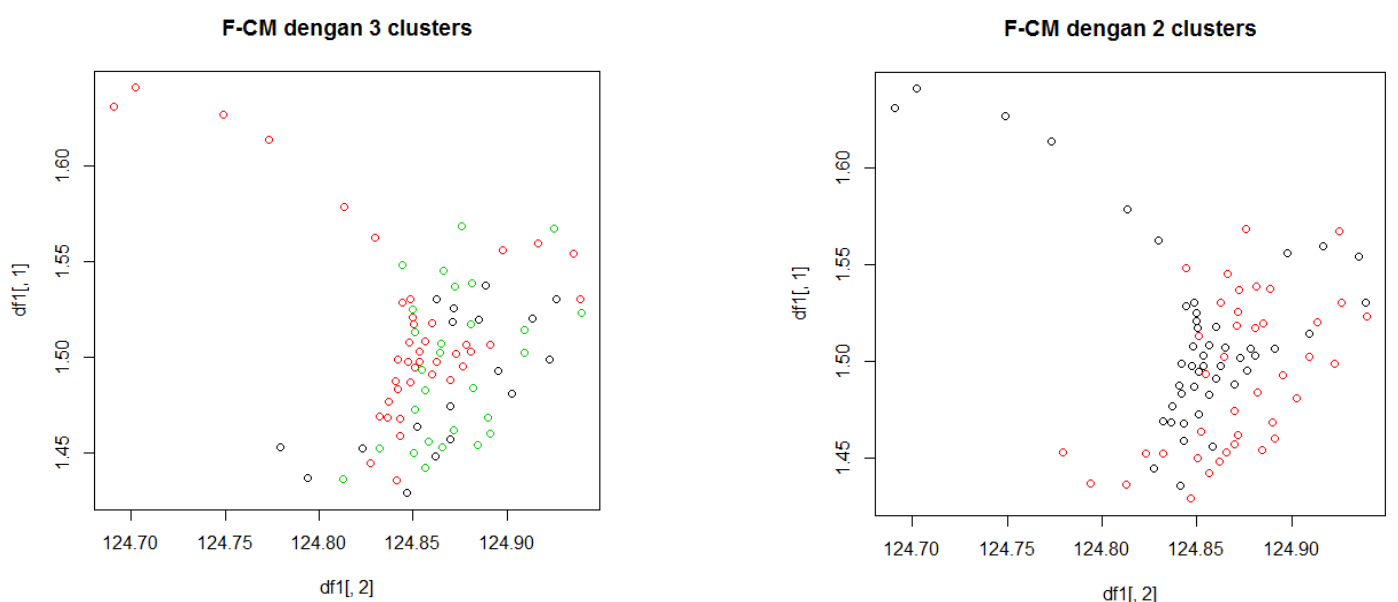

Gambar 4. Hasil Klaster di wilayah Kotamdya Manado menggunakan parameter $m=2$ untuk klaster $\mathrm{c}=3$ dan $\mathrm{c}=2$

Banyaknya kelompok untuk 3 cluster adalah 28, 18 dan 40 untuk masing-masing cluster. Sedangkan perbandingan keanggotaan untuk pengelompokkkan dengan 2 cluster adalah 46 untuk kelompok pertama dan 40 untuk kelompok kedua.

Tabel 1. Dearajat Keanggotaan dari 86 wilayah untuk menentukan posisi klaster

\begin{tabular}{|c|c|}
\hline Derajat keanggotaan untuk 3 cluster & Derajat keanggotaan untuk 2 cluster \\
\hline $\begin{array}{lllll}0 & 0.068544467 & 0.028198993 & 0.90325654\end{array}$ & $\begin{array}{lll}0 & 0.9332550630 .066744937\end{array}$ \\
\hline $\begin{array}{lll}1 & 0.0783401150 .033862004 & 0.88779788\end{array}$ & $\begin{array}{lll}1 & 0.923033832 & 0.076966168\end{array}$ \\
\hline 20.1061136470 .0482545840 .84563177 & 20.8983145570 .101685443 \\
\hline 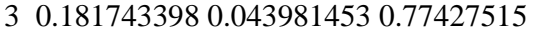 & 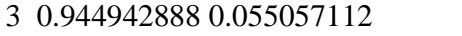 \\
\hline $\begin{array}{lllll}4 & 0.053312508 & 0.018282741 & 0.92840475\end{array}$ & 40.9606362320 .039363768 \\
\hline $\begin{array}{llll}5 & 0.832615763 & 0.126952684 & 0.04043155\end{array}$ & 50.0991907060 .900809294 \\
\hline $\begin{array}{llll}6 & 0.054748440 & 0.021583460 & 0.92366810\end{array}$ & 60.9466661840 .053333816 \\
\hline $\begin{array}{llll}7 & 0.088260415 & 0.0381758620 .87356372\end{array}$ & 70.9155942740 .084405726 \\
\hline $\begin{array}{lll}8 & 0.0872750770 .0384390520 .87428587\end{array}$ & 80.9144044240 .085595576 \\
\hline $\begin{array}{llll}9 & 0.962757168 & 0.022498243 & 0.01474459\end{array}$ & 90.2173080200 .782691980 \\
\hline 100.7225958970 .1490277700 .12837633 & 100.3456307760 .654369224 \\
\hline 110.0812107850 .0229311640 .89585805 & 110.9798715870 .020128413 \\
\hline 120.6322950090 .2985851690 .06911982 & 120.0982183320 .901781668 \\
\hline 130.0922931470 .8807094510 .02699740 & 130.1147439800 .885256020 \\
\hline 140.1574817690 .7926901760 .04982806 & 140.1422552150 .857744785 \\
\hline 150.4503667150 .2338372680 .31579602 & 150.5273279600 .472672040 \\
\hline 160.3467519970 .0668751220 .58637288 & 160.8949407930 .105059207 \\
\hline 170.4304386170 .1421985820 .42736280 & 170.7002453490 .299754651 \\
\hline 180.0837047990 .0255561110 .89073909 & 180.9721296970 .027870303 \\
\hline 190.0343886690 .0114263170 .95418501 & 190.9739009850 .026099015 \\
\hline 200.4719392590 .4111222210 .11693852 & 200.1929261610 .807073839 \\
\hline 210.0979893730 .0439752440 .85803538 & 210.9054709320 .094529068 \\
\hline 220.0748419380 .0320298410 .89312822 & 220.9261447420 .073855258 \\
\hline 230.4966590700 .1216035880 .38173734 & 230.6883524020 .311647598 \\
\hline 240.0738773270 .0208644750 .90525820 & 240.9763215830 .023678417 \\
\hline 250.0310925530 .0116430880 .95726436 & 250.9643474780 .035652522 \\
\hline 260.0306835940 .0116553340 .95766107 & 260.9651902750 .034809725 \\
\hline 270.9234131670 .0378708870 .03871595 & 270.3393796180 .660620382 \\
\hline 280.0337635770 .0122063510 .95403007 & 280.9651727610 .034827239 \\
\hline 290.1188825920 .8462480790 .03486933 & 290.1171769090 .882823091 \\
\hline 300.1024653820 .0283051990 .86922942 & 300.9747240110 .025275989 \\
\hline $\begin{array}{lll}31 & 0.0971322220 .035568922 & 0.86729886\end{array}$ & 310.9292286720 .070771328 \\
\hline 320.0589239550 .0175392400 .92353680 & 320.9811508500 .018849150 \\
\hline 330.0099286480 .0032747700 .98679658 & 330.9907123710 .009287629 \\
\hline 340.0616867510 .0255803010 .91273295 & 340.9357583480 .064241652 \\
\hline 350.2215933480 .0554733460 .72293331 & 350.9154550860 .084544914 \\
\hline 360.7095985190 .1180861940 .17231529 & 360.4779367410 .522063259 \\
\hline 370.3876615930 .0803327240 .53200568 & 370.8534612740 .146538726 \\
\hline 380.4528370830 .4811541690 .06600875 & 380.0673633780 .932636622 \\
\hline
\end{tabular}




\begin{tabular}{|c|c|}
\hline Derajat keanggotaan untuk 3 cluster & Derajat keanggotaan untuk 2 cluster \\
\hline 390.6744707650 .0887166880 .23681255 & 390.6488569270 .351143073 \\
\hline 400.5605949630 .3821281010 .05727694 & 400.0472395030 .952760497 \\
\hline 410.2855196180 .6194857940 .09499459 & 410.1770155360 .822984464 \\
\hline 420.0165794020 .0051359040 .97828469 & 420.9961189340 .003881066 \\
\hline 430.7089429520 .0807629960 .21029405 & 430.6410934720 .358906528 \\
\hline 440.0993492540 .0340778260 .86657292 & 440.9495320380 .050467962 \\
\hline 450.0330649190 .0114390830 .95549600 & 450.9782005500 .021799450 \\
\hline 460.0695042190 .0235741170 .90692166 & 460.9643170260 .035682974 \\
\hline 470.4216150520 .4875327320 .09085222 & 470.1255890200 .874410980 \\
\hline 480.3433998520 .0750050040 .58159514 & 480.8769066810 .123093319 \\
\hline 490.7611286730 .1395802910 .09929104 & 490.2770684020 .722931598 \\
\hline 500.0815883480 .8981364310 .02027522 & 500.0845682140 .915431786 \\
\hline 510.0914081970 .8917041280 .01688767 & 510.0482405120 .951759488 \\
\hline 520.3504122430 .5566485370 .09293922 & 520.1554049270 .844595073 \\
\hline 530.5932881750 .3142932240 .09241860 & 530.1354418840 .864558116 \\
\hline 540.3128354360 .5420764520 .14508811 & 540.2697422050 .730257795 \\
\hline 550.3194554950 .0654402980 .61510421 & 550.9032657130 .096734287 \\
\hline 560.8458394600 .0778249960 .07633554 & 560.3308821190 .669117881 \\
\hline 570.1319285330 .0431812830 .82489018 & 570.9324668370 .067533163 \\
\hline 580.2114184630 .0465956860 .74198585 & 580.9454748800 .05 \\
\hline 590.3255570500 .6288787970 .04556415 & 590.0360948780 .963905122 \\
\hline 600.0686936330 .0231395170 .90816685 & 600.9653896240 .034610376 \\
\hline 610.3233938900 .0948186560 .58178745 & 610.8337608450 .166239155 \\
\hline 620.3279195270 .5692317220 .10284875 & 620.1856056100 .814394390 \\
\hline 630.3566035300 .6083460430 .03505043 & 630.0041053130 .995894687 \\
\hline 640.9202368920 .0428047250 .03695838 & 640.2862925640 .713707436 \\
\hline 650.3629755270 .5497296310 .08729484 & 650.1454267180 .854573282 \\
\hline 660.2032895750 .0606166880 .73609374 & 660.8948806050 .105119395 \\
\hline 670.3572930000 .0934434790 .54926352 & 670.8100033140 .189996686 \\
\hline 680.3141283620 .0780753640 .60779627 & 680.8734672530 .126532747 \\
\hline 690.0283486100 .0097310310 .96192036 & 690.9795563560 .020443644 \\
\hline 700.6728743640 .0777026270 .24942301 & 700.6892313420 .310768658 \\
\hline 710.4079448710 .3819994470 .21005568 & 710.3430218920 .656978108 \\
\hline 720.8440298600 .0807461940 .07522395 & 720.3198295280 .680170472 \\
\hline 730.8797344280 .0808759670 .03938960 & 730.1640905510 .835909449 \\
\hline 740.2603781830 .6294682300 .11015359 & 740.2191717560 .780828244 \\
\hline 750.8302903090 .1210989850 .04861071 & 750.1320416670 .867958333 \\
\hline 760.2736963760 .6887214960 .03758213 & 760.0267503300 .973249670 \\
\hline 770.0547452520 .0219679960 .92328675 & 770.9469784010 .053021599 \\
\hline 780.7660591650 .1989971910 .03494364 & 780.0246605700 .975339430 \\
\hline 790.1799373250 .7630866040 .05697607 & 790.1469086900 .853091310 \\
\hline 800.6024801080 .3008383260 .09668157 & 800.1515514550 .848448545 \\
\hline 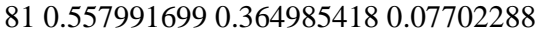 & 810.1069309030 .893069097 \\
\hline 820.1453440130 .8087509970 .04590499 & 820.1356347310 .864365269 \\
\hline 830.8287442730 .1353062980 .03594943 & 830.0705166900 .929483310 \\
\hline 840.9308217130 .0488315570 .02034673 & 840.1179054130 .882094587 \\
\hline 850.4764966580 .2359305150 .28757283 & 850.4957908340 .504209166 \\
\hline
\end{tabular}

\section{Kesimpulan}

Algoritma Fuzzy C-Means dapat digunakan untuk mengelompokkan data pemilih untuk calon walikota Manado pada tahun 2015. Hal ini berguna sebagai acuan pemetaan bagi kandidat yang lain untuk melihat wilayah mana saja yang memberikan respon yang sangat baik ataupun kurang baik sebagai bagian dari demokrasi. Hasil yang dapat dilihat adalah dengan menggunakan 3 cluster dan 2 cluster didapatkan pengelompokkan 28, 18 dan 40 untuk 3 cluster dan pengelompokkan 46 dan 40 untuk 2 cluster. Hasil tersebut dapat dilihat dengan memperhatikan derajat keanggotaan fuzzy-nya. 


\section{Pustaka}

[1] Yang, M. S., Fuzzy Clustering And Its Applications, Department of Applied Mathematic Chung Yuan Christian University ChungLi 32023, Taiwan URL: http://www2.math.cycu.edu.tw/TEACHER/MSYANG/fuzzy-e/fuzzy.htm

[2] Cannon, R. L., Dave, J. V., Bezdek, J. C. 1986. Efficient Implementation Of The Fuzzy CMeans Clustering Algorithms, IEEE Transactions On Pattern Analysis And Machine Intelligence. Vol. Pami-8, No. 2, March 1986

[3] Bezdek, J.C. 1974. Cluster validity with fuzzy sets, J. Cybernet. 3:58-73.

[4] Bezdek, J.C. 1974. Numerical taxonomy with fuzzy sets, J. Math. Biol. 1:57-71.

[5] Bezdek, J.C. 1981. Pattern Recognition with Fuzzy Objective Function Algorithms, Plenum Press, New York.

[6] Bezdek, J.C. 1998. Pattern Recognition in Handbook of Fuzzy Computation, IOP Publishing Ltd., Boston, NY. 